\title{
Determinants of Consumption Behaviors of Korean Pop Culture in Taiwan
}

\author{
Sunmi Lee, National University of Kaohsiung, Taiwan \\ Chien-Hsing Wu, National University of Kaohsiung, Taiwan \\ iD https://orcid.org/0000-0003-1331-8790
}

\begin{abstract}
This paper presents a qualitative analysis of associations between intrinsic (e.g., functional), extrinsic (e.g., social), and cultural consumption values and the consumption behavior of Korean pop cultural contents (KPCC) in Taiwan. Moderation effects of Korean language abilities on associations are also investigated. Results show that intrinsic consumption value has the strongest association with KPCC consumption behaviors. Functional, epistemic, and conditional values have strong associations, whereas emotional and social exhibit weak associations. Cultural value is not a strong predictor of consuming KPCCs due to Korean and Taiwan cultural characteristics not being substantially different. Language abilities weakly moderate relationships between KPCC consumption values and consumption behaviors. Implications and suggestions are addressed. The research contributes findings and implications to the domain of KPCC marketing and retailing in Taiwan.
\end{abstract}

\section{KEYWORDS}

Consumption Behavior, Consumption Value, Cultural Value, Korean Language Ability, Korean Pop Culture Contents

\section{INTRODUCTION}

Among the main drivers of overseas markets for consumer products and services is cultural diversity in traditional and modern culture, arts, and lifestyle. (Jin, Moscardo, \& Murphy, 2017; Chuang \& Lee, 2013; Yalcinkaya, 2008). Korean Pop Culture Contents (KPCC) is a concept covering contents including Korean TV Drama, variety shows, movies, songs, animation, online games and books among others (Malik \& Haidar, 2020; Su, Huang, Brodowsky, \& Kim, 2011; Chuang \& Lee, 2013). Despite an overall preference for cultural products from Europe, United States, and Japan, the awareness and impact of KPCC has increased the potentials of tourist destination especially since the phenomenon of the 'Korean wave' craze a few years ago (Liew \& Sun, 2020). In particular, reports have shown that TV drama has become a major cultural product from Korea (Chuang \& Lee, 2017).

The effect of KPCC consumption on the economy stems from an increase in tourisms as well increased demand for Korean fashion, music, household appliances, electronic devices and cosmetics (Kofice \& Kotra, 2016; Huh \& Wu, 2017). The market share of KPCC products has increased rapidly, and is predicted to become the main supplier of cultural products in Taiwan (KOFICE, 2017). The phenomenon is also taking place in China, Thailand, and Vietnam. Determinants of increased KPCC 
product consumption have been widely studied particularly in Asia Pacific (Kim, Jun, \& Kim, 2018; Huh \& Wu, 2017; Jin, 2012; Kim, Gupta, \& Koh, 2011; Park \& Rabolt, 2009).

Previous studies revealed that consumption behavior is influenced by factors such as culture, fashions and the economy (Table 1). For example, functional (convenience) and emotional values are significant determinants of intention to use continuous social-local-mobile (SoLoMo) services (Yang $\&$ Lin, 2017). Cultural value, conditional value, and epistemic value are all important predictors of global clothing brand image (Park \& Rabolt, 2009). The reasons why consumers spend money on products are therefore multiple. For example, local food consumption behavior derives from functional (quality), emotional, and epistemic values (Choe \& Kim, 2018); customers' decision making is influenced by online reviews, which differ by cultural background; and perceived beneficial image of tourism destination is predicted by consumption value (Phau, Quintal, \& Shanka, 2014). Although Taiwan is the third largest KPCC product consumer after China and Japan (Wu, 2015), there have been few studies of KPCC consumption in the country.

Among the theories describing purchasing behavior, consumption value theory (CVT) (Sheth, Newman, \& Gross, 1991) holds that the main determinants of consumption are functional value (in our case study, represented by the quality and price of KPCC products), epidemic value (novelty of KPCC products), emotional value (happiness induced by KPCC products), social value (friendships potentially resulting from KPCC products), and conditional values (birthday presents). The cultural value theory is proposed (Schwartz, 2006), which inspired a series of studies demonstrating the role of cultural values in buying behavior (Park \& Rabolt, 2009; Kim, Jun, \& Kim, 2018; Fan, Anwar, \& Huang, 2018; Frías-Jamilena et al., 2018). Fan, Anwar, \& Huang (2018) stated that cultural diversity is a remarkable determinant of exports sophistication. However, its effect on KPCC consumption in Taiwan is still under examination. Furthermore, previous studies have revealed the connection between KPCC consumption and Korean language learning (Im, 2015; Sinnenart, 2012), raising the additional question of whether Korean language ability moderates the effect of consumption value and cultural value on KPCC consumption behavior.

To address these issues, this study conducts a qualitative analysis to describe determinants of KPCC consumption in Taiwan, based on consumption value and culture value theories. The data is collected via face-to-face interviews of subjects and deeply analyzed to derive findings. In addition, while some studies have reported that KPCC product consumption is associated with a trend towards Korean language learning in various countries (Im, 2015; Li, 2014), the phenomenon has not been investigated in in Taiwan. We therefore also investigate the moderation effect of Korean language ability on the relationships between consumption and cultural values and Taiwanese KPCC consumption behavior.

\section{LITERATURE REVIEW AND PROPOSITION DEVELOPMENT}

\subsection{KPCC Consumption in Taiwan}

Acceptance of foreign culture-based products is usually influenced by cultural, economic, and political factors in oversea marketing (Abosag \& Brennan, 2017). Taiwan was the first example of KPCC success abroad, which started with Korean songs and then included Korean dramas and movies. For example, $45.8 \%$ of KPCC consumption in Taiwan is represented by TV dramas and reality shows (KOFICE, 2017), while variety shows, movies and songs are gaining broad popularity (Liew \& Sun, 2020). To reveal the determinants linked to consumption behaviors, Table 1 presents a summary of proposed links between consumption value determinants and consumption behaviors (intention, acceptance, decision making). Findings are as follows.

Five major determinant categories, namely consumption value, cultural value, fashion value, technological value (online reviews), and economic value (monetary value), as well as their 
Table 1. Determinants of consumption behavior (intention, acceptance, brand image, decision-making)

\begin{tabular}{|c|c|c|c|c|}
\hline Behavior & Variables & $\begin{array}{l}\text { Operational } \\
\text { categories }\end{array}$ & Main findings & References \\
\hline Local food consumption & $\begin{array}{l}\text { Functional (quality, price), } \\
\text { Prestige, Interaction, } \\
\text { Emotional, Epistemic } \\
\text { values, Cultural } \\
\text { background (moderator) }\end{array}$ & $\begin{array}{l}\text {-Consumption } \\
\text { value } \\
\text { Cultural value }\end{array}$ & $\begin{array}{l}\text { - Functional (quality), Emotional, } \\
\text { and Epistemic values are significant } \\
\text { determinants. } \\
\text { - Cultural background partially } \\
\text { moderates effects of relationships } \\
\text { between variables }\end{array}$ & $\begin{array}{l}\text { Choe and Kim } \\
(2018)\end{array}$ \\
\hline P2P downloading & $\begin{array}{l}\text { Social value, Epistemic } \\
\text { value, Morality, Fashion } \\
\text { involvement (moderator) }\end{array}$ & $\begin{array}{l}\text { - Consumption } \\
\text { value } \\
\text { - Fashion value }\end{array}$ & $\begin{array}{l}\text { - Social and Epistemic values } \\
\text { are associated significantly with } \\
\text { downloading behavior } \\
\text { - Fashion involvement moderates } \\
\text { effect of epistemic value on } \\
\text { downloading behavior }\end{array}$ & $\begin{array}{l}\text { Chen et al. } \\
(2008)\end{array}$ \\
\hline $\begin{array}{l}\text { Customers' consumption } \\
\text { decision making }\end{array}$ & $\begin{array}{l}\text { Cultural difference, online } \\
\text { review }\end{array}$ & $\begin{array}{l}\text { - Cultural value } \\
\text { - Technological } \\
\text { value }\end{array}$ & $\begin{array}{l}\text { - Consumers with the same cultural } \\
\text { background regard online reviews } \\
\text { more useful than all reviewers }\end{array}$ & $\begin{array}{l}\text { Kim, Jun, and } \\
\text { Kim (2018) }\end{array}$ \\
\hline $\begin{array}{l}\text { Digital item purchase } \\
\text { intention }\end{array}$ & $\begin{array}{l}\text { Functional, Social, } \\
\text { Epistemic, Emotional, } \\
\text { Conditional values }\end{array}$ & $\begin{array}{l}\text { - Consumption } \\
\text { value }\end{array}$ & $\begin{array}{l}\text { Functional (quality), Social, and } \\
\text { Emotional values are associated } \\
\text { significantly with purchase intention }\end{array}$ & $\begin{array}{l}\text { Kim et al. } \\
(2011)\end{array}$ \\
\hline $\begin{array}{l}\text { Hedonic digital artifacts } \\
\text { acceptance }\end{array}$ & $\begin{array}{l}\text { Visual value, Social value, } \\
\text { Playfulness value, Money }\end{array}$ & $\begin{array}{l}\text { - Consumption } \\
\text { value } \\
\text { - Economic value }\end{array}$ & $\begin{array}{l}\text { Visual, Playfulness, and Money are } \\
\text { significant determinants }\end{array}$ & $\begin{array}{l}\text { Turel et al. } \\
\text { (2011) }\end{array}$ \\
\hline $\begin{array}{l}\text { Taiwanese consumer } \\
\text { attitude toward location }\end{array}$ & $\begin{array}{l}\text { Culture background, } \\
\text { product character }\end{array}$ & $\begin{array}{l}\text { - Cultural value } \\
\text { - Functional } \\
\text { value }\end{array}$ & $\begin{array}{l}\text { - Consumers' parasocial relationship } \\
\text { with a character is associated } \\
\text { significantly with attitude toward } \\
\text { location for high perceived cultural } \\
\text { proximity between Taiwan and } \\
\text { Korea. }\end{array}$ & $\begin{array}{l}\text { Su et al. } \\
(2011)\end{array}$ \\
\hline $\begin{array}{l}\text { Intention of continuous } \\
\text { SoLoMo service use }\end{array}$ & $\begin{array}{l}\text { Functional (convenience } \\
\text { and benefit), Social, } \\
\text { Epistemic, Emotional, } \\
\text { Conditional, Fashion } \\
\text { values, information } \\
\text { overload and social } \\
\text { overload (moderators) }\end{array}$ & $\begin{array}{l}\text { - Consumption } \\
\text { value } \\
\text { - Fashion value }\end{array}$ & $\begin{array}{l}\text { - Functional (convenience), Social, } \\
\text { Emotional, Epistemic, and fashion } \\
\text { values are significant determinants. } \\
\text { - Information load and social } \\
\text { overload are significant moderators. }\end{array}$ & $\begin{array}{l}\text { Yang and Lin } \\
(2017)\end{array}$ \\
\hline $\begin{array}{l}\text { Virtual purchasing value of } \\
\text { teenagers }\end{array}$ & $\begin{array}{l}\text { Benefits arising from } \\
\text { premium membership, } \\
\text { Decoration, Fun, Status, } \\
\text { and Money }\end{array}$ & $\begin{array}{l}\text { - Consumption } \\
\text { value } \\
\text { - Economic value }\end{array}$ & $\begin{array}{l}\text { Money, Social, Functional, } \\
\text { Conditional, Emotional, Epistemic } \\
\text { are main determinants }\end{array}$ & $\begin{array}{l}\text { Mantymaki } \\
\text { and Salo } \\
(2015)\end{array}$ \\
\hline $\begin{array}{l}\text { Loyalty and use intention } \\
\text { of mobile location-based } \\
\text { services }\end{array}$ & $\begin{array}{l}\text { Monetary, Functional, } \\
\text { Social, Emotional, } \\
\text { Conditional, Epistemic } \\
\text { value }\end{array}$ & $\begin{array}{l}\text { - Consumption } \\
\text { value } \\
\text { - Economic value }\end{array}$ & $\begin{array}{l}\text { Monetary, Functional } \\
\text { (Convenience), Emotional, and } \\
\text { Conditional values are significant } \\
\text { determinants }\end{array}$ & Pura (2005) \\
\hline $\begin{array}{l}\text { Global brand image of } \\
\text { clothing }\end{array}$ & $\begin{array}{l}\text { Cultural Value, } \\
\text { Consumption Value }\end{array}$ & $\begin{array}{l}\text { - Consumption } \\
\text { value } \\
\text { - Cultural value }\end{array}$ & $\begin{array}{l}\text { Cultural value, conditional value } \\
\text { and epistemic value are important } \\
\text { determinants. }\end{array}$ & $\begin{array}{l}\text { Park and } \\
\text { Rabolt (2009) }\end{array}$ \\
\hline $\begin{array}{l}\text { Repurchase decision for } \\
\text { music products in Taiwan }\end{array}$ & Consumption value & $\begin{array}{l}\text { - Consumption } \\
\text { value }\end{array}$ & $\begin{array}{l}\text { Functional, emotional and epistemic } \\
\text { values are significant determinants }\end{array}$ & $\begin{array}{l}\text { Wu, Tao, and } \\
\text { Lin }(2016)\end{array}$ \\
\hline $\begin{array}{l}\text { Perceived beneficial image } \\
\text { of tourism destination }\end{array}$ & $\begin{array}{l}\text { Functional, Social, } \\
\text { Epistemic, Emotional, } \\
\text { Conditional }\end{array}$ & $\begin{array}{l}\text { - Consumption } \\
\text { value }\end{array}$ & $\begin{array}{l}\text { Emotional, Epistemic, Social, and } \\
\text { Functional values are significantly } \\
\text { related to beneficial image of } \\
\text { tourism destination }\end{array}$ & $\begin{array}{l}\text { Phau et al. } \\
\text { (2014) }\end{array}$ \\
\hline
\end{tabular}


combinations have been associated in previous studies with buying intention, product acceptance, attitude toward brand image, and consumption decision-making.

In addition, while some studies concentrated only on a single value (consumption value) others examined combinations of two values (consumption value and cultural value). Certain sub-values (functional value, emotional value and social value) produced inconsistent results, and some were significant in a study but not in others (conditional value and social value). Others (cultural value) seem to consistently affect consumption decision-making.

Finally, a variety of behaviors have been covered by the studies including repurchase intention of music (Wu, Tao, \& Lin, 2016), online downloading (Chen, Shang, \& Lin, 2008), consumption attitudes regarding locations (Su et al., 2011), consumption decision-making (Kim, Jun, \& Kim, 2018), perceived beneficial image of tourism destination (Phau et al., 2014), digital item purchase intention (Kim et al., 2011), and hedonic digital artifacts acceptance (Turel, Serenko, \& Bontis, 2010).

Overall, the summary demonstrates the importance of consumption and cultural values in the development of buying behavior (Park \& Rabolt, 2009). In the present research, we propose and qualitatively examine a model to predict antecedents of KPCC consumption specifically in Taiwan, based on the theory of consumption value and culture value theory.

\subsection{Consumption Value}

Consumption value theory advocates that consumers' buying decision depend on multiple forms of consumption values (Sheth et al., 1991), including functional, social, emotional, epistemic, and conditional value. It is applied to prediction of consumption behavior and its associated values, reasons for purchasing a specific product, use of a particular product or service, and selection of trademark or brand (Sheth et al., 1991; Yang \& Lin, 2017).

To explore effects of value perceptions of KPCC consumption on behavior, this study groups the five consumption values listed above into two categories: intrinsic and extrinsic value (Holbrook, 2006). Intrinsic value refers to the internal consciousness or cognition of functional (quality and accessibility of KPCC), emotional (happiness and sadness evoked by KPCC), and epistemic values (knowledge and playfulness induced by KPCC). Extrinsic value (including social and conditional values) are perceived by consumers depending on a specific situation or circumstance, such as friendships (KPCC as a birthday present) and social status (KPCC used to develop social status or friendships).

\subsection{Intrinsic Consumption Value}

\subsubsection{Functional Value}

Consumers are generally aware of practical and physical features of products such as quality, function, price and service. In the case of Korean pop culture, contents, price, fun, quality, and accessibility are aspects of functional value. We analyzed functional value based on the four subvalues of price, fun, quality, and accessibility. We selected price over economic utility to focus on consumers actually spending money of products (Soutar \& Sweeney, 2001). Fun derived from KPCC products has a positive relation with perceived value (Chuang \& Lee, 2013). Quality is the sum of the characteristics of KPCC satisfying consumers' needs (Kim et al., 2011; Wu, Tao \& Lin, 2016). Convenient access resulting from continuous online availability and multiple choice of devices also influences consumption willingness (Wu et al., 2016).

\subsubsection{Epistemic Value}

The epistemic value of a product or service refers to induced curiosity, novelty, and pursuit of exploratory behavior (Sheth et al., 1991; Mantymaki \& Salo, 2015; Sung, Hartley, Vanman, \& Phau, 2016), and may drive consumption of not required items exclusively due to their entertainment effect (Chen \& Lin, 2015; Sung et al., 2016). For example, epistemic value is significantly associated with a 
positive perception of the tourist destination (Phau et al., 2014). In South Korea, the image of clothing brands is built upon hedonistic factors (Park \& Rabolt, 2009). To reveal the links between epistemic value and KPCC consumption, this study explores curiosity, novelty or knowledge demands that constitute a reason for people consuming KPCC.

\subsubsection{Emotional Value}

Emotional value refers to a feeling aroused in consumers as a result of a product. Consumers develop positive or negative emotions when watching a Korean TV drama, which may lead to future consumption of similar products. Emotional value can therefore nurture behavioral desires (Tsai and Bagozzi, 2014).

Previous studies on emotional value produced some mixed results. Pura (2005) concluded that emotional value significantly promotes the intention to use mobile location-based services, which are supported by studies in digital items purchase intention (Kim et al., 2011), SoMoLo services (Yang \& Lin, 2017) and local food consumption behavior (Choe \& Kim, 2018). Chen, \& Fiore (2017) reported that hedonic benefits is associated with consumption attitude of consumers in Taiwan. In contrast, Park \& Rabolt (2009) showed that emotional value is not a significant factor behind global brand image in the fashion sector. Moreover, Song \& Qu (2017) reported that positive emotions significantly mediated the effect of hedonic value on customer satisfaction.

In summary, the effect of emotional value on consumption behavior may differ by type of products or services. We explore the effect of emotion value on consumption behavior (Drouvelis and Grosskopf, 2016) in the particular case of KPCC consumption in Taiwan. To that aim we develop the following proposition and sub-propositions:

P1: Intrinsic consumption value is associated with KPCC consumption behavior.

P1-1: Functional value is associated with KPCC consumption behavior.

P1-2: Epistemic value is associated with KPCC consumption behavior.

P1-3: Emotional value is associated with KPCC consumption behavior.

\subsection{Extrinsic Consumption Value}

\subsubsection{Social Value}

Consumers may purchase products or services to establish an association with socioeconomic or cultural groups (Yang \& Lin, 2017; Mantymaki \& Salo, 2015; Kim et al., 2011; Sheth et al., 1991). Thus, one of the purposes of acquiring a Korean music product may be to emulate the behavior of friends who consume such products. Previous studies indicated that the effect of social value on purchasing behavior may vary. For example, social value is a significant determinant of P2P music downloading intention (Chen, 2008), digital consumption (Kim et al., 2011) and positive views on tourist destinations (Phau et al., 2014), showing that social associations may also influence personal beliefs and preferences. In contrast, social value was not a significant determinant of both local food consumption (Choe \& Kim, 2018) and hedonic digital artifacts acceptance (Turel et al., 2010). KPCC products convey social status in Taiwan's society, and we thus argue that this value promote KCPP consumption in the country.

\subsubsection{Conditional Value}

Conditional value refers to perceived utility of a product or service under specific circumstances. It occurs in situations where consumers temporarily change desires in order to associate with certain social groups. For example, a birthday gift, seasonal Christmas song, poster of a Korean super star, or first house may acquire a conditional value when someone starts a family. Conditional value has an effect on virtual purchase value for teenagers (Mantymaki and Salo, 2015), mobile location-based service (Pura, 2005), and global fashion brand image (Part \& Rabolt, 2009), but is not a significant 
determinant of local food consumption behavior (Choe \& Kim, 2018), digital item purchase (Kim et al., 2011), SoLoMo service use (Yang \& Lin (2017), perceived image of tourism destination (Phau et al., 2014), and P2P downloading behavior (Chen et al., 2008). Some KPCC purchases take place at events, parties with significant links to Korean culture. Therefore we propose the following propositions:

P2: Extrinsic consumption value is associated with KPCC consumption behavior.

P2-1: Social value is associated with KPCC consumption behavior.

P2-2: Conditional value is associated with KPCC consumption behavior.

\subsection{Cultural Value}

Culture and its complex meanings consists of practices, symbols, norms and values in a society (Schwartz, 2006; Park \& Rabolt, 2009; Fan, Anwar, \& Huang, 2018; Choi, Seo, Wanger, \& Yoon, 2018; Malik \& Haidar, 2020). Schwartz (2006) categorized culture into the seven dimensions of autonomy (cultural broadmindedness and curiosity, exciting and varied life styles), embeddedness (respect for social order and tradition, obedience, security, wisdom), egalitarianism (responsibility, equality, social justice, mutual help, and honesty), hierarchy (social power, authority, humility, and wealth), harmony (peace, unity with nature, and environment protection), and mastery (ambition, success and competence).

Products can provide insights into culture (Zimmerman, 2015). Cultural values produce remarkable influences on various behaviors such as consumption (Choe \& Kim, 2018), decisionmaking (Kim, Jun \& Kim, 2018), location of travel (Su et al., 2011), brand image development (Park \& Rabolt, 2009), and communication (Zimmerman, 2015; Malik \& Haidar, 2020). For example, Park \& Rabolt (2009) reported that egalitarianism, affective autonomy, intellectual autonomy, and harmony values are more relevant to global brand image formation in Americans, while South Koreans are more likely to consider hierarchy value. Sue et al. (2011) reported that a parasocial relationship with a product character induces cultural proximity between Taiwan and Korea. Malik \& Haidar (2020) also reported that power hierarchy is one of characteristics to be considered an online community practice of Korean Pop-music, which likely demonstrates the potential effect of cultural value on online social behaviors. These findings imply that cultural values can induce communication styles toward consumption behaviors.

Taiwan and South Korea have similar profiles regarding the seven cultural domains (Schwartz, 2006), especially in the case of embeddedness and autonomy. However, egalitarianism and harmony are more characteristic of Taiwan, while hierarchy and mastery are more prominent in South Korea. To reveal effect of cultural value on KPCC consumption, we therefore define the third proposition:

P3: Cultural value is associated with KPCC consumption behavior.

\subsection{Korean Language Ability}

Given the cultural similarities between Taiwan and South Korea, it is not surprising that KPCC products were reported to improve the image of Korea and appreciation of Korean culture in Taiwan (Im, 2015; Shon \& Jeon, 2011; Sineenart, 2012). Shon \& Jeon (2011) reported from an analysis of 797 Korean language learners that learning motivation increases when interest in popular culture is higher. This finding is supported by Sineenart (2012) that $60 \%$ of survey respondents in Thailand interested in Korean drama, film, and music are willing to learn Hangul (Korean characters). Im (2015) also reported that popular culture was the second main reason for studying Korean language provided by a sample of 266 students. In summary, interest in or knowledge of Korean language is expected to correlate with consumption of KCPP products. We therefore proposed the fourth propositions: 
Figure 1. Conceptual model

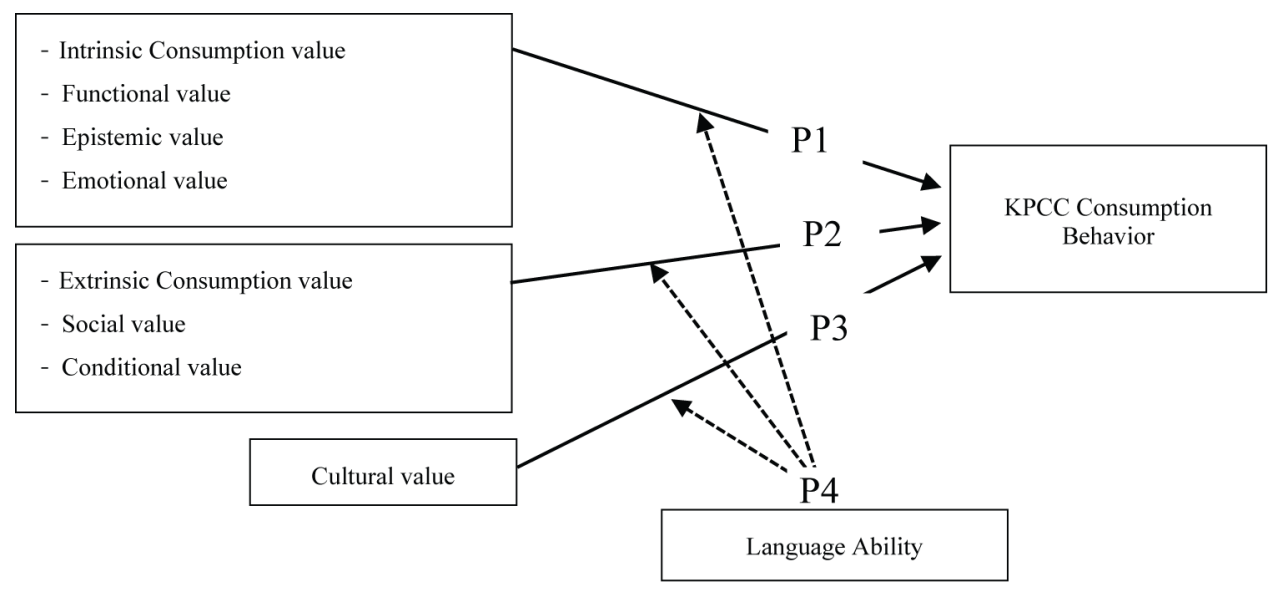

P4: Language ability moderates the effects of consumption value on KPCC consumption behavior.

P4-1: Language ability moderates the effects of intrinsic consumption value on KPCC consumption behavior.

P4-2: Language ability moderates the effects of extrinsic consumption value on KPCC consumption behavior.

P4-3: Language ability moderates the effects of cultural value on KPCC consumption behavior

\section{METHOD}

\subsection{Research Model}

The research is an empirical qualitative study that deepens the understanding and reveals the determinants of the consumption behaviors of KPCC via face-to-face interviews. The research model (Figure 1) based on the defined propositions includes two predictors of KPCC consumption behavior (consumption value and cultural value) and a moderation variable (Korean language ability). Consumption value adopts two states (intrinsic and extrinsic).

\subsection{Interview Questionnaire}

We designed an interview questionnaire to obtain information on subject background (gender and age), KPCC consumption behaviors (TV drama, variety shows, movies, and songs), consumption seniority, consumption frequency, expenditure, and activeness), and Korean language ability (Table 2). We also collected information on concepts, comments, perceptions, and cognition with respect to consumption and cultural values. For example, the question 'Are you satisfied with the quality of KPCC you consume? Why?' provided information on the variable 'functional value'.

We adopted the language ability scale created by the American Council on the Teaching of Foreign Languages (ACTFL, 2017). The guidelines are divided into five proficiency levels: novice, intermediate, advanced, superior, and distinguished. Each of these (except superior and distinguished) is subdivided into low, mid and high scales. Listening, speaking, reading and writing abilities are assessed separately. For example, high scale at intermediate level corresponds to "I can participate with ease and confidence in conversations on familiar topics. I can usually talk about events and experiences in various time frames. I can usually describe people, places, and things. I can handle social interactions in everyday situations, sometimes even when there is an unexpected complication." 
Figure 2. Proposition test results

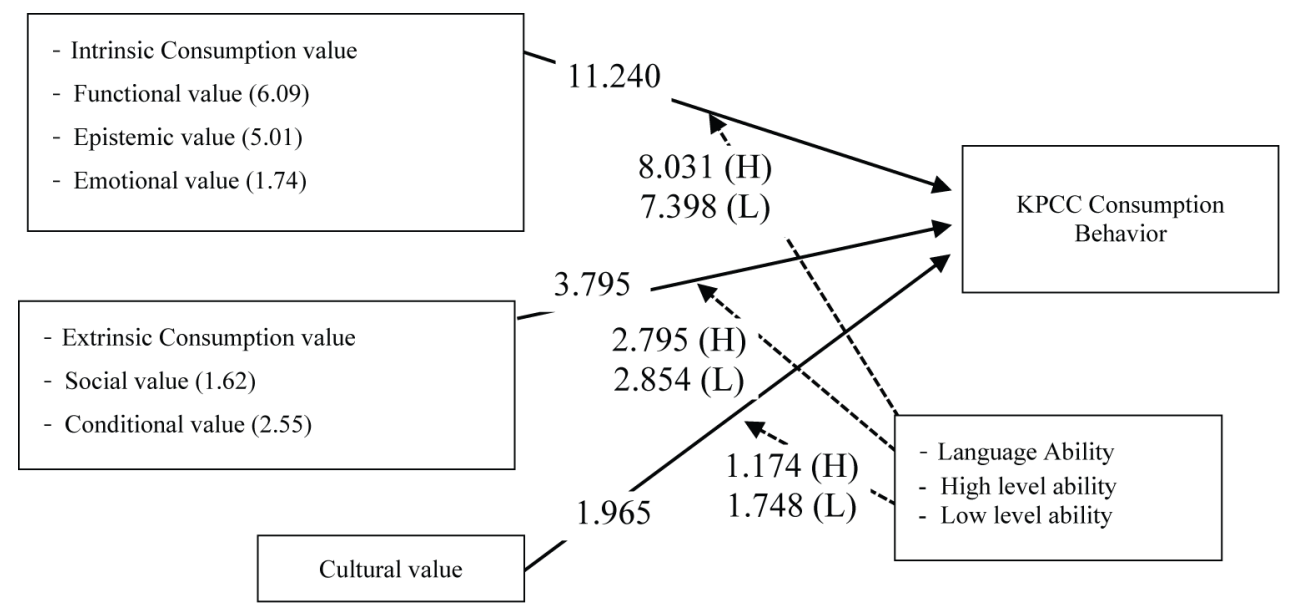

Language ability of our sampled subjects was self-reported at interviews (Lopatovska and Arapakis, 2011) based on ACTFL guidelines, otherwise the reviewer tested and assessed the subjects.

\subsection{Sample and Interview Plan}

The survey used the snowball sampling approach to reach KPCC consumers. To start the survey, a first KPCC consumer was contacted via local colleges, and was asked to suggest consumers of KPCC products.

The survey adopted a three-phase approach. In the 'before' phase, the interviews were prepared, conducted, and recorded using an electronic device upon subjects' acceptance. Otherwise, a video interview was adopted and conversation contents were written down. All interview protocols and non-verbal reactions are written in memos. Data were supplemented by follow-up interviews whenever necessary.

In the 'during' phase, a rapport with subjects was established (Creswell, 2006) with in depth interviews conducted with no strict time limitation.

In the 'after' phase, data were coded through a three-step sequence where potential determinants were generalised through open coding, links between determinants and consumption intention were established through axis coding, and overall integration, elaboration, and association development were based on core determinants through selective coding (Creswell, 2006).

To process voice records and memos, subject number was coded based on interview date and order. Voice recording file, documented file after typing and memos were coded by subject. Transcripts were produced from audio data and general concepts were manually highlighted based on the concept of axis coding. Finally, occurrence frequency of concepts was used to identify potential determinants of KPCC consumption behaviors.

\section{RESULT AND DISCUSSION}

\subsection{Descriptive Statistics}

Data were collected in Taiwan from January to March 2018 and interviews took an hour on average. There were 26 subjects interviewed with demographic statistics, consumption behaviors, and language ability (Table 3). The study adopted face-to face interview approach to collect data. This approach allows subjects having enough time to express their comments, thoughts, opinions, and answers. To 
Table 2. Designed interview questionnaire

\begin{tabular}{|c|c|}
\hline Variables & Questions \\
\hline KPCC & $\begin{array}{l}\text { The following questions assess your experiences, opinions, comments, and expectations when } \\
\text { consuming Korean Pop Culture Contents (KPCC) in Taiwan. }\end{array}$ \\
\hline KPCC1 & $\begin{array}{l}\text { Please enter a number as preference for items you are willing to consume; leave it blank if not willing. } \\
\square \text { Korean TV Drama } \\
\square \text { Korean Variety Shows } \\
\square \text { Korean Movies } \\
\square \text { Korean Songs } \\
\square \text { Korean Animation } \\
\square \text { Korean Online Games } \\
\square \text { Korean Books } \\
\square \text { Others: }\end{array}$ \\
\hline KPCC2 & $\begin{array}{l}\text { How long have you been consuming KPCCs? How and why? } \\
\square \text { Less than } 5 \text { years } \square 5-10 \text { years } \square \text { More than } 10 \text { years }\end{array}$ \\
\hline KPCC3 & $\begin{array}{l}\text { In consuming multiple cultural contents, how frequently do you consume Korean products on average in } \\
\text { comparison with other countries? Why? } \\
\square \text { Less than half } \square \text { About half } \square \text { More than half }\end{array}$ \\
\hline KPCC4 & $\begin{array}{l}\text { How much money (TWD) do you spend consuming KPCCs each time? } \\
\square \text { None } \square \text { Under } 1000 \square \text { More than } 3000\end{array}$ \\
\hline KPCC5 & $\begin{array}{l}\text { Overall, are you an active KPCC consumer? Which number best to represent your activity? } \square 1 \square 2 \square \\
3 \square 4 \square 5\end{array}$ \\
\hline Consumption value & $\begin{array}{l}\text { The following questions assess your knowledge, experience, and expectation about perceived value } \\
\text { when consuming Korean pop culture contents (KPCC) in Taiwan. }\end{array}$ \\
\hline Functional & $\begin{array}{l}\text { 1. Do you think the KPCC you consume is affordable (price)? Why? } \\
\text { 2. Are you satisfied with the quality of KPCC you consume? Why? } \\
\text { 3. Do you think the KPCCs you consume are enjoyable? Why? } \\
\text { 4. Do you think KPCC is easy and convenient to access for consumption? Why? }\end{array}$ \\
\hline Epistemic & $\begin{array}{l}\text { 1. Do you think you can learn anything about Korea through consuming KPCC? Describe any } \\
\text { experiences. } \\
\text { 2. Do you agree that consuming KPCC can offer new indirect experiences? How? } \\
\text { 3. Does consuming KPCC satisfy your curiosity? Why? }\end{array}$ \\
\hline Emotional & $\begin{array}{l}\text { 1. How do you feel when consuming KPCC? Why? } \\
\text { 2. Describe your feelings during your experiences with KPCC. }\end{array}$ \\
\hline Social & $\begin{array}{l}\text { 1. Do you think you can feel social sympathy by consuming KPCC? Why? } \\
\text { 2. Do you think you belong to a particular group by consuming KPCC? Describe the group. } \\
\text { 3. Do you think you can build a personal image by consuming KPCC? Describe the image. }\end{array}$ \\
\hline Conditional & $\begin{array}{l}\text { 1. Do you think you sometimes need to consume KPCC in particular situations? Describe the situations. } \\
\text { 2. Do you think you sometimes need to consume KPCC in particular holidays or activities? Describe the } \\
\text { holidays or activities. }\end{array}$ \\
\hline \multirow[t]{4}{*}{ Cultural value } & $\begin{array}{l}\text { The following questions assess your knowledge, opinions, experience, and expectations regarding } \\
\text { cultural value when consuming Korean pop culture contents (KPCC) in Taiwan. }\end{array}$ \\
\hline & $\begin{array}{l}\text { 1. How familiar are you with Korean culture? Why do you say so? Can you list some of its } \\
\text { characteristics? Which one or ones you think impress you mostly? }\end{array}$ \\
\hline & $\begin{array}{l}\text { 2. Do you think that KPCC contains important cultural features you want to imitate? If so, describe a } \\
\text { few of them. }\end{array}$ \\
\hline & $\begin{array}{l}\text { 3. Do you have experience practicing cultural values discovered while consuming KPCC? What was it } \\
\text { like? What do you feel after that experience? }\end{array}$ \\
\hline \multirow[t]{2}{*}{ Language ability } & The following questions are used to acquire information about your Korean language ability \\
\hline & $\begin{array}{l}\text { 1. Can you speak Korean? If so, how long have you been learning? Did you have special reasons to learn } \\
\text { it? If not, are you willing to learn? Why? } \\
\text { 2. Please select your level of Korean language ability according to your can-do statement. } \\
\square 1 \square 2 \square 3 \square 4 \square 5 \square 6 \square 7 \square 8 \square 9 \square 10\end{array}$ \\
\hline
\end{tabular}


Table 3. Demographic features of sample

\begin{tabular}{|l|l|l|}
\hline \multicolumn{1}{|c|}{ Gender } & \multicolumn{1}{c|}{ Number of subjects } & \multicolumn{1}{c|}{ Percentage (\%) } \\
\hline Male & 5 & 19.2 \\
\hline Female & 21 & 80.8 \\
\hline Age & & \\
\hline Under 20 & 2 & 7.7 \\
\hline $21-30$ & 21 & 80.8 \\
\hline $31-40$ & 2 & 7.7 \\
\hline $41-50$ & 1 & 3.8 \\
\hline
\end{tabular}

effectively explore data from subjects, the study only accepted subjects who were noticed and agreed with the whole interview process. Despite 26 subjects who agreed to participate in the interview might be not considerably big enough for the study, the data collected was considered relevant and comprehensive for the study.

First, most subjects are female (80.8\%) and aged from 21 to 30 (80.8\%), confirming the general pattern of foreign KPCC consumers (Jin, 2012).

Second, 13 out of 26 subjects preferred consuming KPCC songs (50\%), followed by drama (42.3\%) and variety shows (7.7\%) (Table 4). However, among the products that subject consume the most, TV drama is the most popular, followed by variety shows and movies. The difference between preferred and most consumed content indicates that consumption patterns spread from one type of KPCC to another.

Third, average consumption seniority is about 7 years, implying a remarkable depth of KPCC consumption in Taiwan. In most subject (53\%), KPCC products represent over half of all consumed foreign cultural contents. Consumers with top preference on songs are more willing to consume KPCC products (CDs or concerts). The degree KPCC consumption is about 3.8 on the five-point agreement scale, which reveals that Taiwan's KPCC consumers update information on KPCC.

Finally, 11 subjects (42.3\%) exhibit high level of Korean language ability, whereas 15 subjects $(57.7 \%)$ show low ability. Willingness to learn Korean language due to KPCC consumption is about $35 \%$, and $50 \%$ for other purposes such as education and job applications.

\subsection{Coding Analysis}

At the stage of open coding, the interview did not direct or elaborate answers unless required for mutual understanding (Creswell, 2006). Audio data were transcribed and transcripts presented to subjects to confirm they represented their true views. At the stage of axial coding, transcripts were carefully read to extract key concepts related to research arguments (consumption value, Korean language ability, culture tendency).

Table 5 exemplifies how the axial coding process was implemented based on notes taken regarding KPCC consumption behaviors, cultural values, consumption value, and language ability. For example, subject "18012702" said she had no knowledge of Korean language, but was happy to listen to Korean music with Chinese subtitles, and a note was taken regarding the role of Korean language ability in KPCC consumption. Moreover, one of the reasons she enjoyed the songs was to happily experience social values, and a note was taken about the cultural value of hierarchy is a predictor of KPCC consumption.

The same was done for intrinsic and extrinsic consumption value. For example, a subject mentioned a desire to try Korean food shown on TV dramas or variety shows (in Table 5). As she adopts Korean food, she starts to enjoy Korean songs. In addition, she learned from TV dramas that 
Table 4. Statistics of consumption behaviors

\begin{tabular}{|c|c|c|}
\hline Content types (top preferences) & Number of subjects & Percentage (\%) \\
\hline Songs & 13 & 50.0 \\
\hline TV dramas & 11 & 42.3 \\
\hline Variety shows & 2 & 7.7 \\
\hline \multicolumn{3}{|l|}{ Content types (multiple choices) } \\
\hline TV drama & 25 & 25.8 \\
\hline Variety show & 20 & 20.6 \\
\hline Movies & 19 & 19.6 \\
\hline Songs & 16 & 16.5 \\
\hline Animations & 5 & 5.2 \\
\hline Online games & 9 & 9.3 \\
\hline Books & 3 & 3.1 \\
\hline \multicolumn{3}{|l|}{ Seniority (Year) } \\
\hline Less than 5 years & 7 & 26.9 \\
\hline $5-10$ years & 15 & 57.7 \\
\hline More than 10 years & 4 & 15.4 \\
\hline \multicolumn{3}{|l|}{ Frequency (\%) } \\
\hline Less than $50 \%$ & 5 & 19.2 \\
\hline More than $50 \%$ & 14 & 53.8 \\
\hline $100 \%$ & 7 & 26.9 \\
\hline \multicolumn{3}{|l|}{ Expenditure (Unit: NTD) } \\
\hline None & 11 & 42.3 \\
\hline Under 1000 & 12 & 46.2 \\
\hline More than 1000 & 3 & 11.5 \\
\hline \multicolumn{3}{|l|}{ Activeness (Degree) } \\
\hline $1 \& 2$ & 5 & 19.2 \\
\hline 3 & 2 & 7.7 \\
\hline 4 & 11 & 42.3 \\
\hline 5 & 8 & 30.8 \\
\hline \multicolumn{3}{|l|}{ Language ability level } \\
\hline 1 & 15 & 57.7 \\
\hline 2 & 6 & 23.1 \\
\hline 3 & 2 & 7.7 \\
\hline 4 & 3 & 11.5 \\
\hline \multicolumn{3}{|l|}{ Learning willingness } \\
\hline No & 4 & 15.4 \\
\hline Yes, for KPCC purpose & 9 & 34.6 \\
\hline Yes, but for purposes other than KPCC & 13 & 50.0 \\
\hline
\end{tabular}


Table 5. An example at stage of axial coding

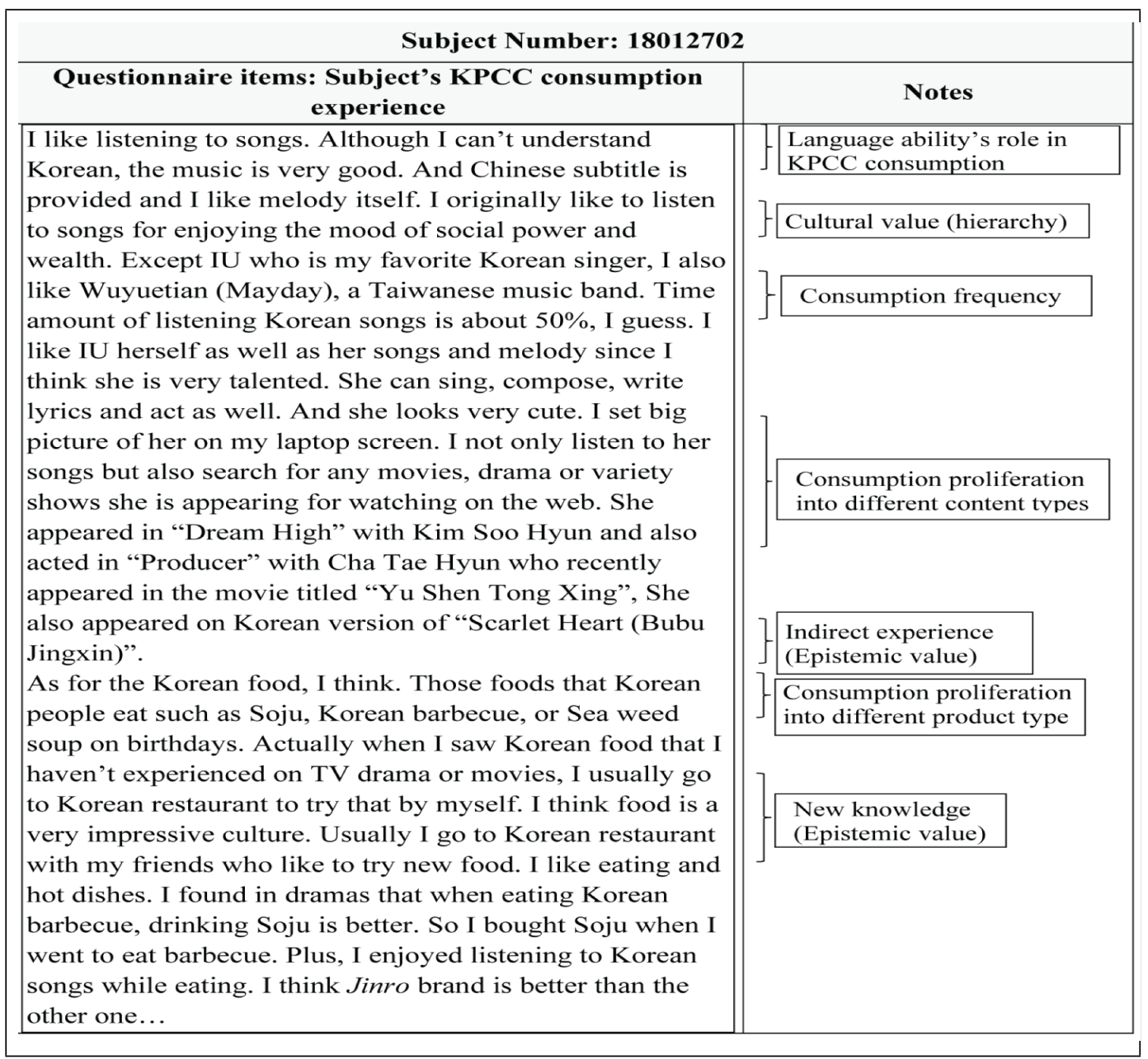

drinking Soju (Korean wine) is pleasant when having a Korean barbecue. This indicates an indirect experience (TV drama leads to Korean food) and a new concept (Soju and Korean barbecue go well together). Accordingly, two notes were taken. The first is that consumption expands into different product types. The second is the epistemic value behind KPCC consumption behavior, with KPCC consumption implying the search for knowledge or novelty.

Finally, at the stage of selective coding, notes were summarized and 13 key concepts were derived (Table 6). According to their definitions, three determinants in the category of intrinsic value were obtained, in which quality satisfaction, cost effectiveness, and real time accessibility were grouped into the determinant of functional value, new knowledge acquisition and indirect experience into the determinant of epistemic value, and sense of belonging and pride into the determinant of emotional value. As for the extrinsic category, group with similar interest represented the determinant of social value, while particular activity and particular purpose were grouped into the determinant of conditional value. Cultural value is represented by perceived hierarchy and perceived mastery. The key concepts were used to mark subjects' transcripts.

It should be noticed that some subjects indicated that a main reason they consumed KPCC was to follow the online Korean wave trend. Although crowd culture is increasingly popular, we excluded 
Table 6. Key concepts and definition (implication)

\begin{tabular}{|c|l|l|}
\hline No. & \multicolumn{1}{|c|}{ Key Concepts } & \multicolumn{1}{c|}{ Definition (implications) } \\
\hline 1 & Quality satisfaction & Consumer's satisfaction with any types of KPCC \\
\hline 2 & Cost effectiveness & Consumer's satisfaction with price relative to quality of KPCC \\
\hline 3 & Real time accessibility & Access to KPCC without obstacles in language and time \\
\hline 4 & New knowledge acquisition & Korean culture practiced as part of consumer's life style \\
\hline 5 & Indirect experience & Understanding Korean culture \\
\hline 6 & Sense of belonging & Sense of belonging to a major community \\
\hline 7 & Pride & Pride in being a KPCC consumer \\
\hline 8 & Group with similar interest & Contact consumer groups with similar interests \\
\hline 9 & Particular activity & Experience of activity with KPCC \\
\hline 10 & Particular purpose & Experience of situation with KPCC \\
\hline 11 & Perceived hierarchy & Perception of higher hierarchy in Korean culture \\
\hline 12 & Perceived mastery & Perception of higher mastery in Korean culture \\
\hline 13 & Online crowd culture & Following the online trend of Korean wave \\
\hline
\end{tabular}

this key concept for being similar to social value, and to preserve social value as a determinant of KPCC consumption.

The frequency of occurrence of each key concept was recorded along with implications, and propositions were tested based on the numerical relationship (association strength) between determinants (consumption value and cultural value) and KPCC consumption behavior represented by items in Table 4 .

The association strength of a behavior item is computed from the number of marks corresponding to each key concept. Total association strength of a determinant group, or AsSt (DG), is obtained via Equation (1). Types of KPCC are songs, TV dramas, and variety shows, with scale weights equal to $1 / 3$. Three scales of seniority, frequency, and expenditure are used, with scale weights equal to $1 / 6$, $2 / 6$, and $3 / 6$, respectively. Finally, there are five scales in activeness with scale weights of $1 / 15,2 / 15$, $3 / 15,4 / 15$, and $5 / 15$, respectively:

$$
\operatorname{AsSt}(D G)=\sum_{i=1}^{3} \frac{T_{i}}{N_{i}} \times w_{i}+\sum_{j=1}^{3} \frac{S_{j}}{N_{j}} \times w_{j}+\sum_{k=1}^{3} \frac{F_{k}}{N_{k}} \times w_{k}+\sum_{l=1}^{3} \frac{E_{l}}{N_{l}} \times w_{l}+\sum_{m=1}^{5} \frac{A_{m}}{N_{m}} \times w_{m}
$$

where:

$T_{i}$ : The number of marks for the $i^{\text {th }}$ type of KPCC appearing in DG.

$N_{i}$ : The total number of marks for the $i^{\text {th }}$ type of KPCC appearing in three determinant groups.

$w_{i}$ : The weight of the $i^{\text {th }}$ type of KPCC: $w_{1}=w_{2}=w_{3}=1 / 3$.

$S_{j}$ : The number of marks for the $j^{\text {th }}$ scale of seniority appearing in DG.

$N_{i}$ : The total number of marks for the $i^{\text {th }}$ scale of seniority appearing in three determinant groups.

$w_{j}$ : The weight of the $j^{\text {th }}$ scale of seniority: $w_{1}=1 / 6, w_{2}=2 / 6, w_{3}=3 / 6$.

$F_{k}$ : The number of marks for the $k^{\text {th }}$ scale of frequency appearing in DG. 
$N_{i}$ : The total number of marks for the $i^{\text {th }}$ scale of frequency appearing in three determinant groups. $w_{k}$ : The weight of the $\mathrm{i}^{\text {th }}$ scale of frequency: $w_{1}=1 / 6, w_{2}=2 / 6, w_{3}=3 / 6$.

$E_{l}$ : The number of marks for the $l^{\text {th }}$ scale of expenditure appearing in DG.

$N_{i}$ : The total number of marks for the $i^{\text {th }}$ scale of expenditure appearing in three determinant groups.

$w_{l}$ : The weight of the $l^{\text {th }}$ scale of expenditure: $w_{1}=1 / 6, w_{2}=2 / 6, w_{3}=3 / 6$.

$A_{m}$ : The number of marks for the $m^{\text {th }}$ scale of activeness appearing in DG.

$N_{i}$ : The total number of marks for the $i^{\text {th }}$ scale of activeness appearing in three determinant groups. $w_{m}$ : The weight of the $m^{\text {th }}$ scale of activeness: $w_{1}=1 / 15, w_{2}=2 / 15, w_{3}=3 / 15, w_{4}=4 / 15, w_{5}=5 / 15$.

\subsection{Proposition Testing}

Marks were counted and entered into tables. Using equation (1), the association strength of intrinsic, extrinsic, and cultural values (ICV, ECV, and $\mathrm{CuV}$ ) to KPCC consumption behaviors was computed (Table 7). For example, the total marks of songs appearing in manuscripts is 72 (47 in the category of intrinsic value, 20 in extrinsic, and 5 in cultural value). The association strength of songs to ICV, $\mathrm{ECV}$, and $\mathrm{CuV}$ are 0.653, 0.278, and 0.069 (47/72, 20/72 and 5/72, respectively). ANOVA test reveals that association to ICV is significantly stronger than that to ECV and $\mathrm{CuV}(\mathrm{F}=178.84, p<0.0001)$ with no significant difference between $\mathrm{ECV}$ and $\mathrm{CuV}$.

The total association strength for ICV, ECV, and CuV are 11.240, 3.975 and 1.965 respectively. Accordingly, Proposition 1 (ICV is associated with KPCC consumption behavior) is supported by an association strength of 11.240. Proposition 2 and 3 (ECV and $\mathrm{CuV}$ are associated with KPCC consumption behavior) are more weakly supported (3.975 and 1.965). The association strengths of the five consumption values are presented in Table 8. Proposition 1-1 (functional value) and 1-2 (epistemic value) are strongly supported (association strength of 6.086 and 5.011, respectively), Proposition 2-2 (conditional value) is adequately supported (2.545), and Proposition 1-3 (emotional value) and 2-1 (social value) are not supported (1.742 and 1.617, respectively). The ANOVA test reveals that association strength of functional value is significantly higher than other types $(\mathrm{F}=40.61$, $p<0.0001)$. Epistemic value shows the second higher association strength, which is significantly higher than association strength of cultural, emotional, and social values.

As for the moderation effect of language ability (Table 9), in the determinant group of ICV the gain of association strength is higher at high level than at low level (8.031 and 7.398). However, in both ECV and $\mathrm{CuV}$, the gain at high level is lower than at low level (2.795 and 2.854 in ECV, 1.174 and 1.748 in $\mathrm{CuV}$ ). The results of $t$ test show no significant difference between high and low level for intrinsic, extrinsic, and cultural values. These findings imply that language ability of Taiwan's consumers seems not to be a moderator of KPCC consumption behaviors.

\subsection{Discussion and Implications}

\subsubsection{Discussion}

Intrinsic consumption value shows the highest association strength to KCPP consumption, and functional and epistemic values ( $\mathrm{AS}=6.087$ and 5.011, respectively) as the main contributors. These findings are consistent with those by Choe \& Kim (2018), Chen et al. (2008), and Yang \& Lin (2017). For the functional value of KPCC, product quality was described in multiple ways in interview transcripts, such as speedy plot development, song lyrics, singers, art design in games, and overall consumer's satisfaction. In the cases of drama or song, there is no specific question regarding price over quality due to free online access to some products. Consumers of movies or games, and active consumers of song made comments that price is generally affordable.

As for epistemic value, manners and food culture are the main components of Korean culture embodied in consumer's life style or habits, issues, but a few subjects also mentioned acquisition of 
Table 7. Test results of proposition P1, P2 and P3

\begin{tabular}{|c|c|c|c|c|}
\hline \multicolumn{2}{|c|}{ KPCC consumption behavior } & \multicolumn{3}{|c|}{ Determinant groups } \\
\hline & & \multicolumn{3}{|c|}{ Association strength } \\
\hline & & ICV (P1) & ECV (P2) & $\mathrm{CuV}(\mathbf{P 3})$ \\
\hline \multirow[t]{3}{*}{ Type } & Songs & 0.653 & 0.278 & 0.069 \\
\hline & TV dramas & 0.667 & 0.167 & 0.167 \\
\hline & Variety Shows & 0.600 & 0.400 & 0.000 \\
\hline \multirow[t]{3}{*}{ Seniority (year) } & Less than 5 & 0.609 & 0.348 & 0.043 \\
\hline & $5 \sim 10$ & 0.681 & 0.217 & 0.101 \\
\hline & More than 10 & 0.654 & 0.154 & 0.192 \\
\hline \multirow[t]{3}{*}{ Frequency (\%) } & Less than half & 0.708 & 0.167 & 0.125 \\
\hline & About half & 0.598 & 0.268 & 0.134 \\
\hline & More than half & 0.743 & 0.257 & 0.000 \\
\hline \multirow[t]{3}{*}{ Expenditure (NTD) } & None & 0.700 & 0.067 & 0.233 \\
\hline & $1 \sim 1000$ & 0.650 & 0.300 & 0.050 \\
\hline & Over 1000 & 0.545 & 0.273 & 0.182 \\
\hline \multirow[t]{5}{*}{ Activeness } & 1 & 0.750 & 0.083 & 0.167 \\
\hline & 2 & 0.700 & 0.200 & 0.100 \\
\hline & 3 & 0.684 & 0.000 & 0.316 \\
\hline & 4 & 0.542 & 0.373 & 0.085 \\
\hline & 5 & 0.756 & 0.244 & 0.000 \\
\hline \multicolumn{2}{|c|}{ Total association strength } & 11.240 & 3.795 & 1.965 \\
\hline \multicolumn{2}{|l|}{ ANOVE } & \multicolumn{3}{|c|}{$F=178.84^{* * *}, p<0.0001 ; \mathrm{ICV}>\mathrm{ECV}=\mathrm{CuV}$} \\
\hline
\end{tabular}

Notes: (1) ICV: Intrinsic consumption value, ECV: Extrinsic consumption value, CuV: Cultural value. (2) The total original marks appeared in ICV, ECV, and $\mathrm{CuV}$ is 460,175 , and 70, respectively. (3) The total weighted marks in ICV, ECV, and CuV is $142.83,55.20$, and 20.63, respectively.

indirect knowledge of social structure, politics, or hierarchical conflicts in Korea. Thus, novelty is a main reason for consumption of KPCC in Taiwan. This finding supports the report by Kim et al. (2008) that less knowledgeable about Korean had a higher willingness to visit Korea after experiencing Korean food.

Regarding emotional value, although sense of belonging or pride is mentioned in subject responses, it does not seem to significantly contribute to KPCC consumption behavior in comparison with other values. This finding is according to the reports by Park \& Rabolt (2009) and Chen et al. (2008), but consistent with reports by Choe \& Kim (2018), Kim et al. (2011), Mantymaki \& Salo (2015), and Yang \& Lin (2017). Since consumption is generalized at a high level, consumers do not experience a sense of belonging or pride from consumption of rarely consumed products.

In addition, extrinsic value (external and passive value perceptions) reveals a weak association strength. This implies that Taiwan's consumers do not buy KPCC mainly due to social or conditional values (association strength $=1.617$ and 2.545 , respectively). This finding is not according to reports by Mantymaki \& Salo (2015), Wu, Tao, \& Lin (2016), and Kim et al. (2011). As for social value, although some consumers reported contacting fan groups to exchange information on KPCC product, such behaviors are relatively rare. The same is true for conditional value. Specific activities by KPCC consumers mainly include discussion with their friends, and specific purposes include change of 
Table 8. Test results of sub-propositions

\begin{tabular}{|c|c|c|c|c|c|c|}
\hline \multirow{3}{*}{\multicolumn{2}{|c|}{ KPCC consumption behavior }} & \multicolumn{5}{|c|}{ Sub-determinants } \\
\hline & & \multicolumn{5}{|c|}{ Association strength } \\
\hline & & FV (P1-1) & EpV (P1-2) & $\begin{array}{c}\text { EmV } \\
\text { (P1-3) }\end{array}$ & SV (P2-1) & CV (P2-2) \\
\hline \multirow[t]{3}{*}{ Type } & Songs & 0.448 & 0.194 & 0.060 & 0.164 & 0.134 \\
\hline & TV dramas & 0.244 & 0.378 & 0.178 & 0.044 & 0.156 \\
\hline & Variety Shows & 0.333 & 0.267 & 0.000 & 0.133 & 0.267 \\
\hline \multirow[t]{3}{*}{ Seniority (year) } & Less than 5 & 0.341 & 0.205 & 0.091 & 0.182 & 0.182 \\
\hline & $5 \sim 10$ & 0.355 & 0.290 & 0.113 & 0.097 & 0.145 \\
\hline & More than 10 & 0.429 & 0.333 & 0.048 & 0.048 & 0.143 \\
\hline \multirow[t]{3}{*}{ Frequency (\%) } & Less than half & 0.429 & 0.381 & 0.000 & 0.095 & 0.095 \\
\hline & About half & 0.282 & 0.268 & 0.141 & 0.127 & 0.183 \\
\hline & More than half & 0.486 & 0.200 & 0.057 & 0.114 & 0.143 \\
\hline \multirow[t]{3}{*}{ Expenditure (NTD) } & None & 0.348 & 0.348 & 0.217 & 0.087 & 0.000 \\
\hline & $1 \sim 1000$ & 0.368 & 0.242 & 0.074 & 0.137 & 0.179 \\
\hline & Over 1000 & 0.333 & 0.333 & 0.000 & 0.000 & 0.333 \\
\hline \multirow[t]{5}{*}{ Activeness } & 1 & 0.300 & 0.400 & 0.200 & 0.100 & 0.000 \\
\hline & 2 & 0.222 & 0.333 & 0.222 & 0.000 & 0.222 \\
\hline & 3 & 0.385 & 0.385 & 0.231 & 0.000 & 0.000 \\
\hline & 4 & 0.296 & 0.259 & 0.037 & 0.167 & 0.241 \\
\hline & 5 & 0.488 & 0.195 & 0.073 & 0.122 & 0.122 \\
\hline \multicolumn{2}{|l|}{ Total } & 6.087 & 5.011 & 1.742 & 1.617 & 2.545 \\
\hline \multicolumn{2}{|l|}{ ANOVA } & \multicolumn{5}{|c|}{$\mathrm{F}=40.61 * * *, p<0.0001 ; \mathrm{FV}>\mathrm{EpV}>\mathrm{CV}=\mathrm{EmV}, \mathrm{CV}>\mathrm{SV}, \mathrm{EmV}=\mathrm{SV}$} \\
\hline
\end{tabular}

Notes: (1) FV: Functional value, EpV: Epistemic value, EmV: Emotional value, SV: Social value, CV: Conditional value. (2) The total original marks appeared in FV, EpV, EmV, SV, and CV is 230, 170, 60, 75, 100, respectively. (3) The total weighted marks appeared in FV, EpV, EmV, SV, and CV is 73.23, $52.07,17.53,22.97$, and 32.23 , respectively.

mood, listening ability practice, or relieving stress. However, the behaviors are not general and unable to promote KPCC consumption as strongly as functional and epistemic values.

Finally, cultural value presents the lowest association strength, and is therefore not the main predictor of KPCC products in Taiwan. This finding is not consistent with reports by Kim, Jun, and Kim (2018) in the research context of consumption decision making and Park \& Rabolt (2009) in the brand image of clothing. Despite it reveals not a strong association strength, hierarchy is more relevant than mastery according to subjects' transcripts. Most subjects mentioned that they would directly simulate hierarchy perceived through consumption of KPCC, such as manners. This can be attributed to the fact that hierarchy in Korean culture, related to authority and humbleness, is embodied in distinctive or visual ways such as a high honorific use of Korean language, bowing when greeting elders, and order of starting a meal according to position or age. Taiwan is similar to Korea in autonomy types (Schwartz, 2006), but slightly higher in egalitarianism and harmony. Overall, however, cultural value perceived by Taiwanese consumers perceived is presently not a predictor of KPCC consumption behaviors. 
Table 9. Test results of moderation effect of language ability

\begin{tabular}{|c|c|c|c|c|c|c|c|}
\hline \multicolumn{2}{|c|}{ KPCC consumption behavior } & \multicolumn{6}{|c|}{ Determinant groups } \\
\hline & & \multicolumn{2}{|c|}{ ICV (P4-1) } & \multicolumn{2}{|c|}{ ECV (P4-2) } & \multicolumn{2}{|c|}{$\mathrm{CuV}$ (P4-3) } \\
\hline & & \multicolumn{6}{|c|}{ Association strength } \\
\hline & & $\mathbf{H}$ & $\mathbf{L}$ & $\mathbf{H}$ & $\mathbf{L}$ & $\mathbf{H}$ & $\mathbf{L}$ \\
\hline \multirow[t]{3}{*}{ Type } & Songs & 0.675 & 0.630 & 0.250 & 0.296 & 0.075 & 0.074 \\
\hline & TV dramas & 0.667 & 0.667 & 0.250 & 0.111 & 0.083 & 0.222 \\
\hline & Variety Shows & 0.000 & 0.000 & 0.000 & 0.000 & 0.000 & 0.000 \\
\hline \multirow[t]{3}{*}{ Seniority (year) } & Less than 5 & 0.000 & 0.621 & 0.390 & 0.310 & 0.122 & 0.069 \\
\hline & $5 \sim 10$ & 0.653 & 0.000 & 0.000 & 0.000 & 0.000 & 0.000 \\
\hline & More than 10 & 0.733 & 0.750 & 0.200 & 0.000 & 0.067 & 0.250 \\
\hline \multirow[t]{3}{*}{ Frequency (\%) } & Less than half & 0.000 & 0.579 & 0.250 & 0.211 & 0.078 & 0.211 \\
\hline & About half & 0.625 & 0.000 & 0.000 & 0.000 & 0.000 & 0.000 \\
\hline & More than half & 0.750 & 0.625 & 0.250 & 0.375 & 0.000 & 0.000 \\
\hline \multirow{3}{*}{$\begin{array}{l}\text { Expenditure } \\
\text { (NTD) }\end{array}$} & None & 0.000 & 0.682 & 0.250 & 0.045 & 0.078 & 0.273 \\
\hline & $1 \sim 1000$ & 0.717 & 0.000 & 0.000 & 0.000 & 0.000 & 0.000 \\
\hline & Over 1000 & 0.455 & 0.571 & 0.273 & 0.429 & 0.273 & 0.000 \\
\hline \multirow[t]{5}{*}{ Activeness } & 1 & 0.000 & 0.769 & 0.250 & 0.077 & 0.078 & 0.154 \\
\hline & 2 & 0.833 & 0.000 & 0.000 & 0.000 & 0.000 & 0.000 \\
\hline & 3 & 1.000 & 0.600 & 0.000 & 0.000 & 0.000 & 0.400 \\
\hline & 4 & 0.364 & 0.905 & 0.273 & 0.000 & 0.364 & 0.095 \\
\hline & 5 & 0.700 & 0.000 & 0.300 & 1.000 & 0.000 & 0.000 \\
\hline \multicolumn{2}{|c|}{ Total association strength } & 8.031 & 7.398 & 2.795 & 2.854 & 1.174 & 1.748 \\
\hline \multicolumn{2}{|l|}{$t$ test } & \multicolumn{2}{|c|}{$t=0.386, p=0.351$} & \multicolumn{2}{|c|}{$t=0.067, p=0.473$} & \multicolumn{2}{|c|}{$t=-0.790, p=0.218$} \\
\hline
\end{tabular}

Notes: (1) H: High group, L: Low group. (2) ICV: Intrinsic consumption value, ECV: Extrinsic consumption value, CuV: Cultural value. (3) The total original marks in high group in ICV, ECV, and CuV are 282, 107, and 33, respectively. (4) The total weighted marks of high group in ICV, ECV, and CuV are 66.30, 25.20, and 7.57, respectively. (5) The total original marks in low group in ICV, ECV, and CuV are 178, 68, and 37, respectively. (6) The total weighted marks of low group in ICV, ECV, and CuV are 50.10, 21.57, and 9.30, respectively.

\subsubsection{Implications}

This study adopts consumption value and cultural value as the conceptual tools to examine KPCC consumption behavior in Taiwan, with language ability as a moderator. Results show that intrinsic consumption value is a better predictor of KPCC consumption behavior than both extrinsic and cultural values. Korean language ability does not moderate the effects of consumption value and cultural value on KPCC consumption behaviors. These results have theoretical and practical implications.

First, functional and epistemic values have remarkable effects on KPCC consumption. These effects vary by consumption behavior category. For example, functional value has a stronger effect on active KPCC consumers. Consumers who most actively search for KPCC information are more affected by aspects of functional value such as quality, cost-effectiveness and accessibility. This finding is supported by testimonials including: "when I finished studying, I spent over $70 \%$ of my free time watching Korean dramas and variety shows, or chatting with friends about Korean culture...Access to KPCC is very fast.....As for Korean dramas, firstly, production skill is excellent, the cast have good appearance, moreover, Korean dramas have unique plots not seen in Taiwanese or Chinese 
dramas" (Subject 18012203). This finding bridges a research gap by showing that functional value is the main predictor of KPCC consumption behavior in Taiwan.

Second, epistemic value is found more prominently in consumers of TV drama than of songs or variety shows. Although consumers of songs have knowledge and indirect experience of Korean culture, Korean songs are not the direct sources of knowledge and experiences. This finding is supported by one subject whose top preference is songs: "I know that Korean people eat small living octopus, Kimchi, and fish cake. I learned those things from YouTube clips by foreigners living in Korea. Those people visit many places in Korea and share experiences and knowledge through video clips. Oh, I also know that respect is very important to Korean people since I saw video clip of EXO on YouTube showing that they bow to greet elder singers" (Subject 18020302).

Third, perceived cultural value and emotional value do not strongly affect consumption behavior. As shown in Schwartz (2006), Taiwan and Korea are similar in cultural orientation, although perception of hierarchy and mastery are more distinctive in Korean than Taiwanese culture. This can be seen from a subject's comment that "As for courtesy, I found out that Korean people take politeness seriously. But, that kind of politeness does not seem so binding but just a part of daily life, so natural. All the Korean drama I watch include politeness elements. I think it is worth learning" (Subject 18012205). Interviews showed that Taiwanese consumers do perceive hierarchy and its positively side such as eating etiquette or greetings to elders, but not the negative aspects of hierarchy. This may be the result of KPCC's attempts to portray cultural values positively, or of restrictions on KPCC containing negative contents. Overall, cultural value and emotional value are not strong predictors of KPCC consumption behavior in Taiwan.

Fourth, Korean language ability does not show significant moderation effects on the influence of consumption value and cultural values on KPCC consumption. Regarding language ability, the higher level group has a stronger association with intrinsic consumption value, whereas opposite results hold for extrinsic and cultural values. This is likely to be related to consumption seniority. In our sample, the longer the consumption of KPCC, the higher the Korean language ability through either active or passive learning. Thus, sensitivity may be inversely proportional to KPCC consumption seniority, so that the more consumers are exposed to and familiar with a specific culture, the less sensitive there are to exposure to it.

Finally, Korean language ability also reveals that functional and conditional values have a stronger relationship with consumption behavior in the high language ability group, whereas epistemic and social values have a stronger relationship in the low language ability group. For consumers in the high ability group, quality, cost effectiveness and accessibility are important factors. They also consider specific activities or purposes when making consumption decisions. However, consumers with low language ability, experience or acquisition of indirect experience, and being in a group of people with similar interests are the main factors. These implications are relevant for marketing or Korean language education businesses. There is a difference between general expectation and the evidence we obtained regarding the moderating effect of Korean language ability. Korean language education agents and consultants tends to target big KPCC markets. However, our results show that Korean language ability is not an obstacle to KPCC consumption. Therefore, further research on the purpose of KPCC is needed to assist the Korean education industry in approaching big KPCC markets.

Moreover, effective marketing strategies should be developed to reach distinct group of consumers. For example, viral marketing through fan clubs or fan pages in the local language would be more effective among consumers with limited knowledge of Korean, mainly due to the effect of social value. In contrast, its trends leading to consumption of KPCC for a specific purpose would be more efficient when targeting consumers with high language ability, due to the influence of conditional value. 


\section{CONCLUSION AND LIMITATIONS}

This study has drawn on the importance of KPCC consumption behavior in Taiwan. We have shown that intrinsic consumption value is the factor most strongly associated with consumer's consumption behavior. Among intrinsic value components, functional value indices such as quality, cost efficiency and real-time accessibility, and epistemic value expressed as acquisition of new knowledge and indirect experience are the most strongly related to consumption behavior, whereas emotional value (sense of belonging or pride) shows a weak influence. In comparison to intrinsic value, extrinsic value has a weaker relationship with consumption behavior. Moreover, regardless of Korean language ability of subjects, functional value shows the strongest association with KPCC consumption behavior. However, based on details of consumption behavior such as contents type, consumption seniority, consumption frequency, consumption expenditure, and consumption activeness, consumers with high language ability show a stronger relationship with functional and epistemic values.

The study presented a few limitations. Cosmetics, clothing and food were excluded but should be considered in future studies. More in-depth studies in the effect of culture value on KPCC consumption are also desirable. Through interviews, subjects showed a deep understanding of Korean culture, way of thinking and social structure, as well as more superficial knowledge of table manners and greetings. Understanding in more depth the cultural traits delivered to consumers through indirect experience would contribute to planning and marketing of Korean pop culture contents. Moreover, in addition to the types of consumption values examined in the research, other consumption value of KPCC products may differ in influence of COVID-19 pandemic. Future studies may focus not only on the reexamination of current types of value (e.g., functional value), but also the exploration of potential types of value (e.g., safety value) to relevantly response to changes of consumption environment for traders and marketers in Taiwan. 


\section{REFERENCES}

Abosag, I., \& Brennan, D. R. (2017). Understanding marketing innovativeness in Asia: A research agenda. Asian Business \& Management, 16(4-5), 212-225. doi:10.1057/s41291-017-0027-1

ACTFL Can-Do Statements Progress Indicators for Language Learners. (2017). Retrieved from https://www. actfl.org/publications/guidelines-and-manuals/ncssfl-actfl-can-do-statements

Chen, S. C., \& Lin, C. P. (2015). The impact of customer experience and perceived value on sustainable social relationship in blogs: An empirical study. Technological Forecasting and Social Change, 96, 40-50. doi:10.1016/j. techfore.2014.11.011

Chen, W. C., \& Fiore, A. M. (2017). Factors affecting Taiwanese consumers' responses toward pop-up retail. Asia Pacific Journal of Marketing and Logistics, 29(2), 370-392. doi:10.1108/APJML-01-2016-0013

Chen, Y. C., Shang, R. A., \& Lin, A. K. (2008). The intention to download music files in a P2P environment: Consumption value, fashion, and ethical decision perspectives. Electronic Commerce Research and Applications, 7(4), 411-422. doi:10.1016/j.elerap.2008.02.001

Choe, J. Y., \& Kim, S. (2018). Effects of tourists' local food consumption value on attitude, food destination image, and behavioral intention. International Journal of Hospitality Management, 71, 1-10. doi:10.1016/j. ijhm.2017.11.007

Choi, Y. K., Seo, Y., Wagner, U., \& Yoon, S. (2018). (in press). Matching luxury brand appeals with attitude functions on social media across cultures. Journal of Business Research.

Chuang, L. M., \& Lee, H. E. (2013). Korean wave: Enjoyment factors of Korean dramas in the U.S. International Journal of Intercultural Relations, 37(5), 594-604. doi:10.1016/j.ijintrel.2013.07.003

Creswell, J. W. (2005). Educational Research: Planning, Conducting, and Evaluating Quantitative and Qualitative Research. Pearson Education.

Drouvelis, M., \& Grosskopf, B. (2016). The effects of induced emotions on pro-social behavior. Journal of Public Economics, 134, 1-8. doi:10.1016/j.jpubeco.2015.12.012

Fan, Z., Anwar, S., \& Huang, S. (2018). Cultural diversity and export sophistication. International Review of Economics \& Finance, 58, 508-522. doi:10.1016/j.iref.2018.05.008

Frías-Jamilena, D. M., Sabiote-Ortiz, C. M., Martín-Santana, J. D., \& Beerli-Palacio, A. (2018). Antecedents and consequences of cultural intelligence in tourism. Journal of Destination Marketing \& Management, 8, 350-358. doi:10.1016/j.jdmm.2017.07.006

Holbrook, M. B. (2006). Consumption experience, customer value, and subjective personal introspection: An illustrative photographic essay. Journal of Business Research, 59(6), 714-725. doi:10.1016/j.jbusres.2006.01.008

Huh, C. G., \& Wu, J. (2017). Do Hallyu (Korean wave) exports promote Korea's consumer goods exports? Emerging Markets Finance \& Trade, 53(6), 1388-1404. doi:10.1080/1540496X.2017.1313161

Im, M. K. (2015). Needs analysis for learner-centered cultural class in Korean language teaching: based on the needs analysis of Japanese and Chinese learners of Korean (Unpublished Master Thesis). Graduate School of Yonsei University, Republic of Korea. (in Korean)

Jin, H., Moscardo, G., \& Murphy, L. (2017). Making sense of tourist shopping research: A critical review. Tourism Management, 62, 120-134. doi:10.1016/j.tourman.2017.03.027

Jin, Y. J. (2012). A study on the impact of Korean wave cultural contents on national image, tourism image and revisit intention mainly focus on Taiwanese tourists. Graduate School of Kyunghee University. (in Korean)

Kim, H., Gupta, S., \& Koh, J. (2011). Investigating the intention to purchase digital items in social networking communities: A customer value perspective. Information \& Management, 48(6), 228-234. doi:10.1016/j. im.2011.05.004

Kim, J. M., Jun, M., \& Kim, C. K. (2018). The effects of culture on consumers' consumption and generation of online reviews. Journal of Interactive Marketing, 43, 134-150. doi:10.1016/j.intmar.2018.05.002 
KOFICE \& KOTRA. (2016). A study on the economic effects of the Korean Wave in year 2015. Retrieved from https://www.languagetesting.com/actfl-proficiency-scale (in Korean)

KOFICE (Korea Foundation for International Culture Exchange). (2017). The 7th Global Survey on Korean Popular Culture Contents. Retrieved from http://kofice.or.kr/b20industry/b20_industry_01_view.asp?seq=295 \&page $=1 \&$ find $=\&$ search $=($ in Korean $)$

Li, Z. P. (2014). Study on the Relationship between Korean Learning and Korean Wave: Focusing on the China (Unpublished Master Thesis). Graduate School of Seoul Woman's University, Republic of Korea. (in Korean)

Liew, K. K., \& Sun, M. (2020), Pax Musica and Mnets: Cantopop-Kpop Convergences and Inter-Asia Cultural Mobilities. Made in Hong Kong: Studies in Popular Music, 33-43.

Lopatovska, I., \& Arapakis, I. (2011). Theories, methods and current research on emotions in library and information science, information retrieval and human-computer interaction. Information Processing \& Management, 47(4), 575-592. doi:10.1016/j.ipm.2010.09.001

Malik, Z., \& Haidar, S. (2020). Online community development through social interaction- K-Pop stan twitter as a community of practice. Interactive Learning Environments, 1-19. Advance online publication. doi:10.10 80/10494820.2020.1805773

Mäntymäki, M., \& Salo, J. (2015). Why do teens spend real money in virtual worlds? A consumption values and developmental psychology perspective on virtual consumption. International Journal of Information Management, 35(1), 124-134. doi:10.1016/j.ijinfomgt.2014.10.004

Park, H. J., \& Rabolt, N. J. (2009). Cultural value, consumption value, and global brand image: A cross-national study. Psychology and Marketing, 26(8), 714-735. doi:10.1002/mar.20296

Phau, I., Quintal, V., \& Shanka, T. (2014). Examining a consumption values theory approach of young tourists toward destination choice intentions. International Journal of Culture, Tourism and Hospitality Research, 8(2), 125-139. doi:10.1108/IJCTHR-12-2012-0090

Pura, M. (2005). Linking perceived value and loyalty in location-based mobile services. Managing Service Quality, 15(6), 509-538. doi:10.1108/09604520510634005

Schwartz, S. H. (2006). A theory of cultural value orientations: Explication and applications. Comparative Sociology, 5(2-3), 137-182. doi:10.1163/156913306778667357

Sheth, J. N., Newman, B. I., \& Gross, B. L. (1991). Why we buy what we buy: A theory of consumption value. Journal of Business Research, 22(2), 159-170. doi:10.1016/0148-2963(91)90050-8

Shon, S. H., \& Jeon, N. Y. (2011). A study of language learning motivation of Korean language learners [in Korean]. Journal of Korean Language Education, 22(3), 133-152. doi:10.18209/iakle.2011.22.3.133

Sineenart, S. (2012). The Study on the Influence and the Current State of Korean Wave in Thai Society (Unpublished Master Thesis). Graduate School of Yeungnam University, Republic of Korea.

Song, J., \& Qu, H. (2017). The mediating role of consumption emotions. International Journal of Hospitality Management, 66, 66-76. doi:10.1016/j.ijhm.2017.06.015

Soutar, G., \& Sweeney, J. C. (2001). Consumer perceived value: The development of a multiple item scale. Journal of Retailing, 77(2), 203-220. doi:10.1016/S0022-4359(01)00041-0

Su, H. J., Huang, Y. A., Brodowsky, G., \& Kim, H. J. (2011). The impact of product placement on TV-induced tourism: Korean TV dramas and Taiwanese viewers. Tourism Management, 32(4), 805-814. doi:10.1016/j. tourman.2010.06.020

Sung, B., Hartley, N., Vanman, E., \& Phau, I. (2016). ow can the word "NEW" evoke consumers' experiences of novelty and interest? Journal of Retailing and Consumer Services, 31, 166-173. doi:10.1016/j. jretconser.2016.02.010

Tsai, E. H. T., \& Bagozzi, R. P. (2014). Contribution behavior in virtual communities: Cognitive, emotional and social influences. Management Information Systems Quarterly, 38(1), 143-164. doi:10.25300/MISQ/2014/38.1.07 
Turel, O., Serenko, A., \& Bontis, N. (2010). User acceptance of hedonic digital artifacts: A theory of consumption values perspective. Information \& Management, 47(1), 53-59. doi:10.1016/j.im.2009.10.002

Wu, C. H., Tao, Y. H., \& Lin, Y. M. (2016). Repurchase decision for music products in Taiwan: Physical versus online media, Digital Policy. Regulation \& Governance, 19(4), 302-316. doi:10.1108/DPRG-09-2016-0044

Wu, I. H. (2015). A Study on the processes of importing and indigenizing the Korean wave in Taiwan (Unpublished Master Thesis). Graduate School of Hankuk University of Foreign Studies, Republic of Korea. (in Korean)

Yalcinkaya, G. (2008). A culture-based approach to understanding the adoption and diffusion of new products across countries. International Marketing Review, 25(2), 202-214. doi:10.1108/02651330810866281

Yang, H. L., \& Lin, R. X. (2017). Determinants of the intention to continue use of SoLoMo services: Consumption values and the moderating effects of overloads. Computers in Human Behavior, 73, 583-595. doi:10.1016/j. chb.2017.04.018

Zimmerman, E. (2015). Conversations about culture: How Korean and Japanese cultural products, practices and perspectives are discussed to co-construct cultural understanding in talk. Learning, Culture and Social Interaction, 5, 28-39. doi:10.1016/j.lcsi.2014.10.001

Sunmi Lee is a graduate student of the International Master of Business Administration at National University of Kaohsiung, Kaohsiung, Taiwan. Her research interests include language education, business administration and cultural marketing.

Chien-Hsing Wu is a Professor of the Department of Information Management at National University of Kaohsiung, Kaohsiung, Taiwan. He received his MS and PhD in the department of Systems Science and Industrial Engineering from Binghamton University, State University of New York, New York, USA. His research interests include information management, Internet marketing, and knowledge engineering \& management. He has published several refereed articles in journals such as Information \& Management, Journal of Retailing and Consumer Services, Journal of Enterprise Information Management, Information Processing \& Management, Management Decision, and Internet Research. 